\title{
Responsibility to or for in the physician-patient relationship?
}

\author{
Richard C McMillan Mercer University School of Medicine, Macon, Georgia, USA
}

\begin{abstract}
The threat of malpractice litigation in the United States is encouraging physicians again to assume responsibility for their patients. The fundamental ethical problem, however, is that this approach denies the patient's moral agency. In this essay, responsibility to patients, rather than for them, is discussed as an alternative to the emerging neo-paternalism. Responsibility to avoids the ethical problems of assuming responsibility for moral agents and could reduce the threat of litigation as well.
\end{abstract}

Anyone remotely familiar with health care delivery in the United States is aware that malpractice litigation (or the fear thereof) has become a major factor in that process. In fact, threatened or actual legal action by patients against their physician has become sufficiently commonplace to prompt the evaluation that this is the "era of the "malpractice phenomenon"' (1). That foreboding possibility has brought inordinate pressure to bear on the physician in the practice of his or her profession (2). Whether the threat of suit is real or imagined, a recent study found that many physicians have come to view their relationship with patients and their families 'as an adversarial one in which the clinician's first reaction is self-protection' (3). Although it is only in recent years that some physicians have come to view the physician-patient relationship as a form of partnership (4), it has been rare indeed for the relationship to be viewed as adversarial. Neither colleagues nor foes, patients were simply judged to have nothing of significance to contribute to the medical decisionmaking process. The physician, therefore, assumed responsibility for them and for their care - but always in the patient's best interests.

\section{Responsibility for}

Notwithstanding the fundamental moral requirement that agents must be responsible for themselves (5), the physician-patient relationship has been judged so different from other relationships as to constitute an

\section{Key words}

Responsibility; physician-patient relationship; paternalism.

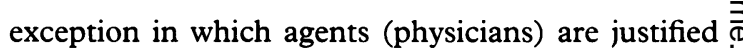
in assuming responsibility for agents (patients possessing decisional capacity). Unlike any other î human need, a significant loss of health renders the $\overrightarrow{\vec{N}}$ patient helpless and, therefore, wholly dependent on $\vec{N}$ the physician. The potential threat posed by this $\mathrm{O}$ need joined with the patient's inability to do anything to help him or herself has been said to create a 'coercive' (6) relationship in which 'to invite a doctor to treat you as a patient is, in certain respects, to invite him to take responsibility for you'(7) [emphasis added]. The high level of expertise possessed by the modern physician makes it very likely that the physician - or one of his more specialized colleagues - can correct or, at least, reduce the effect of the patient's loss of health. This expertise, it has been observed, tends to 'remove the responsibility for health and disease from the layperson's shoulders to those of the health professional, especially the physician ...' (8).

When the growing threat of legal action by patients against physicians is combined with the fact that the physician is ordinarily viewed as finally $:$ responsible for the outcome of the patient's health care and, therefore, as 'the person from whom, if at $\stackrel{\delta}{\circ}$ all, an account will be required' (9), the evolution of a new form of paternalism seems inevitable. The era 음 of the malpractice phenomenon has spawned the 'era of neo-paternalism' - a physician-centred paternalism in which physicians act first in their interest. In this setting, control of the primary variables of the medical encounter seems both a practical and a prudent requirement.

However appealing the time-honoured assumption of responsibility for the patient appears to be in 0 modern health care delivery, control of the principal $\overparen{\complement}$ variable in the relationship - the patient - is possible $\stackrel{\oplus}{+}$ only on the basis of some form of deception or 7 coercion. Persons in relationship interpret $\frac{\vec{D}}{\mathrm{D}}$ behaviour directed towards them and, apart from $\stackrel{\mathbb{P}}{\stackrel{\oplus}{\oplus}}$ deception or coercion employed to control their $\stackrel{\mathbb{Q}}{\propto}$ response, this interpretation interrupts any inherent $\bar{O}$ cause and affect sequence and generates an individuality of response. Niebuhr clearly recognized this dynamic in his discussion of responsibility as: 
'the idea of an agent's action as response to an action upon him in accordance with his interpretation of the latter action and with his expectation of response to his response; and all of this is in a continuing community of agents' (10).

Individuals towards whom our behaviour is directed react in terms of their interpretation of our behaviour in relation to themselves, their goals, and the options for response they deem appropriate. Our behaviour does indeed prompt the interpretation, but, absent intervention intended to control, our behaviour does not cause the response.

When we find ourselves in situations in which we feel we must assume responsibility for other persons, it is necessary to manipulate or control their behaviour to ensure the outcome we desire. At a minimum, we must convince them that the courses of action being chosen for them are far better than any they could possibly choose for themselves (the approach normally and appropriately employed with children and so successfully used in traditional medical paternalism). Failing this, the potential controller must resort to deception or to outright coercion, particularly if the sense of responsibility for is sufficiently strong. In the context of health care delivery, deception or coercion need not be aggressive, but may be quite subtle (for example, failing to reduce the patient's fear or confusion or withholding information pertinent to the patient's condition or therapy). Any number of elements in the relationship will affect the facility with which imposition may be accomplished, but in situations in which an obvious inequality of expertise and skill exists (the power of the physician), surrender is often obtained with surprising ease. Join this inequality with a dependency-creating need related to one's personal welfare (the patient's loss of health) and surrender may be immediate and unconditional.

Whatever the method of control, the fundamental ethical issue is the denial of the patient's moral agency. The assumption of responsibility for a person who possesses the capacity for agency robs that individual of essential elements of his or her humanity. Persons must be responsible for themselves; the responsibility for one's becoming simply cannot be delegated. Every man is in possession of himself as he is ... [This] places the entire responsibility for his existence squarely upon his own shoulders' (11). Furthermore, moral agents are responsible for what happens as a result of their choices. The process of deliberation, decision, and the assumption of responsibility in relationship to one's behaviour is a function of 'the centred totality of [the individual's] being. Each of us is responsible for what has happened through the centre of his self, the seat and organ of his freedom' (12). The assumption of responsibility for oneself and one's actions is, therefore, a principal characteristic of being human and the essence of morality.
Conversely, the denial of choice and responsibility dehumanizes the individual, an ethically unacceptable outcome in any context. The assumption of responsibility for an individual capable of assuming responsibility for herself reduces that individual to an object and the relationship Buber criticized with his 'I-it' category (13) has developed. Without just cause (for example, to prevent one individual from harming another, to protect an individual from unforeseen immediate harm, or to maintain the common good), restriction of one's freedom to assess situations, choose appropriate courses of action, and assume responsibility for those actions denies the individual's humanity and, as experience confirms, is destructive in any context. Considering the outcome, neither the physician's fear of litigation nor the patient's need for health care is a sufficient warrant for the denial of agency.

\section{Responsibility to}

Founded on the fundamental significance of moral agency, the paradigm of responsibility to provides an alternative to a physician-centred neo-paternalism. Human beings make choices and intentionally take actions based on those choices; actions which impact the lives of other persons. Responsibility, then, 'is the affirmation of one's being as the doer in contrast to the acceptance of the role of the object done to' (14). An 'object done to' is not a cause; the reactions of objects are not originated by the object but caused and objects are, therefore, not responsible for those reactions. A 'doer', on the other hand, is a cause; he or she makes things happen which have an impact on other persons and the moral quality of that impact must rest with the doer. When a person is intentionally concerned for the nature of the impact their behaviour has on others, behaves accordingly, and accepts full responsibility for his behaviour, that person has assumed the role of moral agent. The 'crown jewel' of this assumption of responsibility to others is the willingness to consider the sacrifice of self-interest to the interest of others. The assumption of responsibility in this sense is the essence of morality and is an integral expression of being human.

Responsibility, then, should be viewed 'as being accountable "for" one's deeds, whatever they are ...' (15). Rather than assuming responsibility for the decisions and/or behaviour of persons possessing agency, one is responsible for one's actions as those actions have an impact on other persons. Because our lives are interactional, it is unavoidable that our behaviour will have an impact on others. We are responsible for that impact, but only for the impact. Absent deception or coercion, the manner in which an agent reacts is a function of the agency of that individual and is action for which he or she is accountable. Agents are responsible to other agents; agents are responsible for themselves. 
Drawing the limits of responsibility in this fashion is not intended to suggest a benign indifference to the well-being of other persons. Because we live in an interdependent web of life, we must will the good for others in order realistically to will the good for ourselves. Experience teaches even the casual observer that moral good cannot be achieved apart from or at the expense of others. Typically, the good we will for ourselves is the best we know and, therefore, serves as the norm for the good we will for others. It does not follow, however, that our sense of the good is appropriate for other people as they also have their sense of what is best for them. No matter how meritorious the intention, doing good to moral agents without allowing them to accept, modify, or reject that good dehumanizes them. Rather than willing a specific concept of the good for others, willing the good for others is a commitment to helping them achieve their sense of the good - so long, that is, as the good being sought does not violate the moral commitments of the helper. The obligation to will the good for others does not require the surrender of one's moral commitments in the process.

Willing the good for others is frequently simply a matter of counselling them as they attempt to achieve desired outcomes or avoid harm. There are situations in which we judge our vantage point to be better than that of others and occasionally we may even be correct in that assessment. Responsibility to includes the obligation to share insights, clarify options, provide information, give advice, communicate judgments and so on in terms of an outcome we judge to be in an individual's best interest. This counsel, however, is an expression of our best judgment, not of absolute truth. The recipients of this counsel, therefore, remain free to decide what action they will take. It is, after all, an action for which they are responsible.

Although responsibility to affirms the freedom of each moral agent to choose those courses of action which seem most appropriate, this does not require that the action be condoned simply because it was freely and responsibly chosen. That would impose an unacceptable restriction on one's ability to respond responsibly. Choice and the assumption of responsibility for choice is an individual matter. Behaviour, on the other hand, is the dynamic of relationships, affecting both individuals and community. As Niebuhr's understanding of the nature of responsibility clearly indicated, relational behaviour is an ongoing process of mutual responses for which each actor is responsible. To paraphrase a widely accepted legal tenet, one may believe (or choose) whatever one wishes; legal (and ethical) problems may arise when one acts on the basis of one's belief (or choice) (16).

\section{Responsibility to and litigation}

When compared to responsibility for, the implications of responsibility to for the physician-patient relationship are fairly obvious. The implication which may not be so obvious, however, is that responsibility to should reduce the threat of litigation. As a matter of fact, it could be argued that the assumption of $\stackrel{?}{?}$

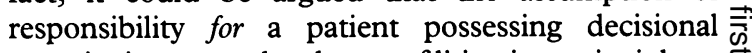
capacity increases the chance of litigation as it violates $\frac{7}{0}$ the thorough-going self-determination which is a $\frac{C}{O}$ basic premise of Anglo-American common law (17). While there may be no way finally to avoid capricious $\vec{\nabla}$ litigation, cultivation of responsibility to in the physician-patient relationship could go far towards of reducing the threat of legal intervention by decreasing $\vec{O}$ the likelihood that patients would find it necessary or appealing to bring suit against their physician.

Nothing said here, however, should be interpreted to mean that physicians are not accountable and $\stackrel{\oplus}{\oplus}$ liable for the health care they provide. The help the physician provides involves a high level of expertise iv and, of course, considerable remuneration. More- $\overrightarrow{\vec{N}}$ over, the fact cannot be ignored that the physician is

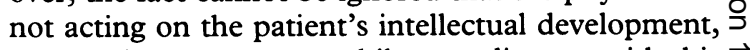
or marriage, or automobile, or dispute with his $\vec{D}$ neighbour; rather, the physician is doing something, 음 often in a most intimate and sometimes invasive manner, to the patient's body. The actions of one $\ddot{\emptyset}$ individual towards another could not be more or intensely personal and accountability and liability, in $\square$ both the moral and legal sense, apply. However, from the standpoint of responsibility $t o$, accountability and liability apply to the physician's actions, not to what the patient may choose to do or not to do on the basis $\stackrel{\mathbb{Q}}{\complement}$ of diagnosis, prognosis, or therapy. The physician, $\overrightarrow{\overrightarrow{\vec{P}}}$ then, is accountable for the competence with which $\frac{9}{\exists}$ treatment is provided and for the quality of any information communicated to the patient. However, when information is sound and is communicated clearly and humanely, the physician should not be held accountable for the reaction the patient or the $\dot{\sigma}$ surrogate may elect to make to the information.

\section{Conclusion}

Responsibility to in the physician-patient relationship emphasizes the importance of both parties in the healing process. Except for the emergency N situation, overt - not tacit - agreement between physician and patient (or surrogate) regarding the ${ }_{0}$ goals of medical treatment is an absolute necessity and the importance of meaningful communication cannot be overemphasized. The physician is noto reduced to a mere adviser or technician impersonally exercising her considerable expertise, nor is the $\stackrel{+}{+}$ patient viewed as no more than a helpless object in desperate need of medical treatment. Rather, both physician and patient remain moral agents with unique contributions to make to the achievement of $\stackrel{\mathbb{Q}}{\mathscr{Q}}$ a shared goal. Medical decisions remain theo responsibility of physicians. Patients, on the other hand, are responsible for value decisions regardingo the outcomes of treatment which best express their sense of responsibility for themselves and to others. 
As it turns out, the concept of responsibility to protects the legitimate interests of both parties in the physician-patient relationship.

Richard C McMillan, BD, EdD, is Professor of Ethics and Humanities, Department of Psychiatry and Behavioral Science, Mercer University School of Medicine, Macon, Georgia, USA.

\section{References and notes}

(1) Siegler M, Goldblath A D. Clinical intuition: a procedure for balancing the rights of patients and the responsibilities of physicians. In: Spicker S F, et al, eds. The law-medicine relation: a philosophical exploration. Dordrecht, Holland: D Reidel Publishing Co, 1981: 19.

(2) A recent survey, reported in the American medical news 1991 Apr 22: 11, indicated that professional liability is the factor which 'interferes most with clinical decision-making'.

(3) McCrary S V, et al. Treatment decisions for terminally ill patients: physicians' legal defensiveness and knowledge of medical law. Law, medicine and health care 1992; 20: 372.

(4) Szasz T S, Hollender M H. The physician-patient relationship. In: Gorovitz S, et al, eds. Moral problems in medicine. Englewood Cliffs, NJ: Prentice-Hall Inc, 1976: 64-67.

(5) Haydon G. On being responsible. The philosophical quarterly 1978; 28: 57.
(6) Hauerwas S M. Authority and the profession of medicine. In: Agich G J, ed. Responsibility in health care. Dordrecht, Holland: D Reidel Publishing Co, 1982: 96.

(7) MacIntyre A. Patients as agents. In: Spicker S F, Engelhardt H T Jr, eds. Philosophical medical ethics: its nature and significance. Dordrecht, Holland: D Reidel Publishing Co, 1977: 205.

(8) Ozar D T. Social ethics, the philosophy of medicine, and professional responsibility. Theoretical medicine 1985; 6: 287.

(9) See reference (5): 55.

(10) Niebuhr H R. The responsible self. New York: Harper and Row, 1963: 65.

(11) Sartre J P. Existentialism. In: Dewey R E, Gramlich F W, Loftsgordon D, eds. Problems of ethics. Toronto: The Macmillan Co, 1961: 316.

(12) Tillich P. Systematic theology [vol 1]. Chicago: The University of Chicago Press, 1951: 184.

(13) Buber M. I and thou [translated by Smith R G]. New York: Charles Scribner's Sons, 1958.

(14) Bugental J F T. The search for authenticity. New York: Holt, Rinehart and Winston Inc, 1965: 23.

(15) Jonas H. The imperative of responsibility. Chicago: The University of Chicago Press, 1984: 90.

(16) Cantwell v Connecticut, 310 US 296, 303-304 (1940).

(17) Natanson v Kline. 350 P 2d 1093 (1960). In: Graber G C, Beasley A D, Eaddy J A. Ethical analysis of clinical medicine. Baltimore: Urban and Schwarzenberg, 1985: 43.

\section{Continued from page 105}

misleading statements suggesting that we had not presented our protocol to a research ethics committee. We consider Dr Evans should have researched this and found out from our hospital the truth of the situation before writing his paper or criticising our child protection work in the media.

David Southall, MD, FRCP, is Professor of Paediatrics in the Academic Department of Paediatrics, University of Keele, North Staffordshire Hospital, Stoke-on-Trent. Martin P Samuels, MD, MRCP, is Consultant Paediatrician in the same department.

\section{References}

(1) Evans D. The investigation of life threatening child abuse and Munchausen syndrome by proxy. Fournal of medical ethics 1995; 21 : 9-13.

(2) Southall D P, Stebbens V A, Rees S V, Lang M H, Warner J O, Shinebourne E A. Apnoeic episodes induced by smothering - two cases identified by covert video surveillance. British medical journal 1987; 294: 1637-1641.

(3) Samuels M P, McClaughlin W, Jacobson R R, Poets C F, Southall D P. Fourteen cases of imposed upper airway obstruction. Archives of disease in childhood 1992; 67: $162-170$.

(4) Samuels M P, Southall D P. Munchausen syndrome by proxy. British journal of hospital medicine 1992; 47: 759-762.

(5) Lightfoot L. Mother seeks inquiry on child abuse doctor. The Sunday Times 1995; Feb 5: 11 (cols 1-4).

(6) BBC Radio Stoke. Jaywalk presented by Jason Dean. 1995 Feb 6, $11.30 \mathrm{am}-2 \mathrm{pm}$. 